\title{
An incidental finding of metastatic gastric cancer to the appendix during diagnostic laparoscopy. A case report and review of the literature.
}

Janaka Lovell ( $\boldsymbol{\sigma}$ janakalovell@gmail.com )

Royal Hobart Hospital https://orcid.org/0000-0002-8473-2633

Aram Cox

Royal Hobart Hospital

Helen Harris

Royal Hobart Hospital

Simon Whitcher

Royal Hobart Hospital

\section{Research Article}

Keywords: Gastric Cancer, Appendix, Appendiceal metastasis, Diagnostic Laparoscopy

Posted Date: February 4th, 2022

DOI: https://doi.org/10.21203/rs.3.rs-1310930/v1

License: (c) (i) This work is licensed under a Creative Commons Attribution 4.0 International License. Read Full License 


\section{Abstract}

Purpose: Gastric cancer is the $6^{\text {th }}$ most common cancer and is a leading cause of death worldwide. Metastases to the appendix is a rare clinical entity of gastric cancer and only 10 cases are reported in the literature to date.

Methods / Results: We present a case of a 74 year-old female who underwent a diagnostic laparoscopy prior to a planned gastric cancer resection for a gastric adenocarcinoma. The appendix was incidentally noted to be macroscopically abnormal during the procedure and was subsequently resected. This was found to contain a metastatic deposit of gastric adenocarcinoma. This resulted in an upstaging of the patient's cancer and, systemic treatment became the management of choice.

Conclusion: This case highlights the importance of diagnostic laparoscopy as part of staging in gastric cancer and underscores the need for a thorough examination, as appendiceal metastasis can be easily missed if not specifically assessed for or not found on work-up imaging.

\section{Background}

Gastric cancer is the 6th most common cancer and remains a leading cause of death worldwide, particularly in East Asia (1). Metastases to the appendix from a primary gastric cancer is a rare clinical entity. Case reports exist for 7 patients who initially presented with acute appendicitis whereby histology revealed the presence of metastatic gastric adenocarcinoma. The onset of acute appendicitis secondary to metastases was within 3 years of diagnosis of the primary cancer for 4 patients. Diagnosis of the primary cancer and acute appendicitis/metastasis was simultaneous for 3 patients (2). There are only an additional 3 reported cases where patients were asymptomatic and diagnosed incidentally by imaging, colonoscopy or during another procedure (3).

Further clarification on the incidence of appendiceal metastasis in gastric cancer is warranted to improve the approach to oncologic surgery and systemic treatments.

Following the CARE checklist format (4), we present the first case of an incidentally discovered appendix specimen containing a metastatic deposit of gastric cancer during diagnostic laparoscopy.

\section{Case Presentation}

We present the case of a 74-year-old female who was diagnosed with a poorly differentiated gastric adenocarcinoma (HER-2 negative / IHC 2 positive / MMR proficient) following an endoscopic biopsy of a $37 \times 15 \mathrm{~mm}$ ulcerated gastric lesion. This is in the setting of a 4-month history of left upper quadrant abdominal pain with associated melaena and fatigue. She has a past medical history salient for leftsided breast cancer treated with a mastectomy and axillary dissection. 
A staging PET-CT (Positron Emission Tomography - Computed Tomography) scan revealed an intensely FDG (fluorodeoxyglucose) avid lesion in the gastric body/antrum with no definite evidence of nodal or distal metastases. FDG avidity was noted in the caecum, however with no corresponding CT abnormality, this was deemed to be physiological in nature (Figure 1). During her workup she presented to the emergency department with ongoing melaena and haematemesis requiring packed red blood cell transfusions. A contrast CT (Figure 2) revealed 2 suspicious, solid, subcapsular liver lesions in segment 2. She also underwent a repeat endoscopy which showed no active bleeding from the gastric lesion.

To further stage her known malignancy and organise subsequent treatment, she proceeded to have a diagnostic laparoscopy during which the liver lesion was resected for histopathology. During this procedure, the appendix was inspected and noted to be macroscopically abnormal. Salient features noted were abnormal thickening, injection and widening of the lower aspect of the vermiform appendix. It was resected and sent to pathology.

\section{Outcome}

The resected liver lesion was deemed to be a sclerosed hemangioma. Intriguingly, the appendiceal specimen was found to have a $50 \mathrm{~mm}$ metastatic deposit, lying $6.5 \mathrm{~mm}$ from the appendiceal base with similar pathological features. Both appendiceal and gastric samples showed similar morphological and immunohistochemical features (figure 3). Both specimens were moderate to poorly differentiated adenocarcinomas which stained positive to cytokeratin AE1/3, CK7 and CDX2. Both had negative staining for CDX2. Considering this, the tumours were deemed to represent the same tumour with a gastric origin favoured.

This patient was discussed at the combined upper gastrointestinal / oncology multi-disciplinary meeting. Due to the poor prognosis of patients with metastatic tumours to the appendix, the consensus decision was for a haemostatic radiation dose (which successfully aborted gastric bleeding from the tumour) followed by palliative chemotherapy with a doublet regimen.

\section{Discussion}

Gastric cancer is a common malignancy in Australia with an estimated 2246 new cases in 2020, representing approximately $1.5 \%$ of all new cancer diagnoses (5). The pattern of metastatic spread differs based on the histological subtype but overall, most of the metastatic disease burden involves the liver (48\%), peritoneum (32\%), lung (15\%), and bone (12\%) (6). Metastatic spread to the appendix is an exceedingly rare phenomenon with only a handful of cases previously reported in the literature $(2,7-16)$. These cases have been summarised in Table 1.

The exact mechanism by which gastric cancer metastasises to the appendix is unknown. A hypothesis is that metastases occur via peritoneal dissemination which then infiltrates through the serosa and subsequently through into the appendiceal lumen $(9,15)$. At some point, this infiltration may cause a 
perforation, causing clinical acute appendicitis with peritonitis. More research into the specific cellular and genetic mechanisms are required to further clarify the exact mechanism of this.

Clinical staging is critical to determine the management pathway. Diagnosis is often initially through endoscopic examination, biopsies, and confirmation through histopathology. Staging should then be routinely performed with cross-sectional CT imaging of the chest, abdomen, and pelvis assessing for the presence of metastatic disease. If at this point surgical resection is indicated, it is recommended that diagnostic laparoscopy is performed to assess for the presence of peritoneal metastatic deposits before surgical resection of the gastric cancer (16).

In most of the reported cases (70\%), the diagnosis was established incidentally secondary to a presentation of presumed simple acute appendicitis. Only after histopathological examination of the appendix specimen was the presence of metastatic gastric cancer revealed. Pina-Oviedo et al (14) described a case where the appendiceal metastasis was discovered through CT staging and confirmed once excised. In another case, Alhadid et al (3) described a patient who underwent a major gastric resection which was then complicated by an internal hernia. This required an extended right hemicolectomy which incidentally identified metastatic cancer within the appendix. Fu et al (10) described a patient who underwent colonoscopy for investigation of anal pain who had previously had a total gastrectomy for gastric adenocarcinoma. Biopsies confirmed metastatic adenocarcinoma to the appendix.

Our case is unique in that, to our knowledge, it is the only case reported where the appendiceal metastasis has been discovered through diagnostic laparoscopy performed just before the planned major gastric resection. As mentioned, the role of diagnostic laparoscopy is a well-established practice, particularly as a method to rule out peritoneal disease burden which is difficult to identify on preoperative cross-sectional imaging (16-18). In this case, the diagnostic laparoscopy upstaged the patient, and the treatment trajectory was altered with a referral to oncology for consideration of chemotherapy. The limitations of preoperative cross-sectional imaging are further demonstrated through this case with several modalities reporting a normal, non-tumorous appendix.

\section{Conclusion}

The General Surgeon should be aware of the possibility, albeit low, of metastatic gastric carcinoma to the appendix in their practice. This case highlights the importance of diagnostic laparoscopy as part of staging in gastric cancer. Particularly, it highlights the need for a thorough examination, as appendiceal metastasis can be easily missed if not specifically assessed for.

Although the likelihood of the appendix being involved is exceedingly rare in gastric cancer, we recommend that it is examined during laparoscopy given the possibility it may be involved, and if it is, early discovery will avoid unnecessary surgical morbidity and mortality. Elucidating the true incidence of asymptomatic appendiceal metastasis may even favour the benefit of oncologic gastric resections with prophylactic appendicectomies. 
We would recommend appendicectomy if discovered due to the possibility of appendicitis, and referral to oncology for consideration of chemotherapy. Further studies are needed to determine the survival of patients with solitary appendiceal metastasis of gastric origin who do or do not undergo adjuvant systemic therapy.

\section{Declarations}

Funding: The authors declare that no funds, grants, or other support were received during the preparation of this manuscript.

Competing Interests: The authors have no relevant financial or non-financial interests to disclose.

Author Contributions: All authors contributed to the study conception and design. Material preparation, data collection and analysis were performed by JL, AC and SW. The first draft of the manuscript was written by $\mathrm{JL}$ and $\mathrm{AC}$ and all authors commented on previous versions of the manuscript. All authors read and approved the final manuscript.

Data Availability: The datasets generated during and/or analysed during the current study are available from the corresponding author on reasonable request.

Ethics Approval: This is an observational case study, no ethical approval is required per the Royal Hobart Hospital ethics committee.

Consent to Participate: Informed consent was obtained from the patient included in the study.

Consent to Publish: The authors affirm that the studied participant provided informed consent for publication of the all images.

\section{Compliance with Ethical Standards:}

Funding: The authors did not receive support from any organization for the submitted work

Conflict of Interest: The authors declare that they have no conflict of interest.

Informed Consent: Informed consent was obtained from the patient included in the study (see supplementary document)

\section{References}

1. Cancer. World Health Organization (WHO). (2021). https://www.who.int/news-room/factsheets/detail/cancer Accessed 9th August 2021.

2. Wang W, Cui T, Mao W. Acute appendicitis caused by metastatic gastric adenocarcinoma: A case report and literature review. Annals of Palliative Medicine. 2021;10(6):7132-7. DOI:10.21037/apm21-1098. 
3. Alhadid D, AlShammari A, Almana H, Aburahmah M. Missed gastric cancer metastasis to the appendix: case report and literature review. Am J Case Rep. 2020;21:e920010. DOI. 10.12659/AJCR.920010.

4. 2013 Care Report Checklist. CARE case report guidelines (2013). https://www.carestatement.org/checklist Accessed 7th August 2021.

5. Australia Government. Stomach cancer statistics. (2020). Available from:

https://www.canceraustralia.gov.au/affected-cancer/cancer-types/stomach-cancer/stomach-cancerstatistics. Accessed 1st August 2021.

6. Riihimäki M, Hemminki A, Sundquist K, Sundquist J, Hemminki K. Metastatic spread in patients with gastric cancer. Oncotarget. 2016;7(32):52307-16. DOI:10.18632/oncotarget.10740.

7. Siddiqui S, Yaseen M, Sajjad K. Metastatic Gastric Carcinoma Presenting as Acute Appendicitis (2020). Cureus 12(4):e7617. DOI: 10.7759/cureus.7617.

8. Tran QB, Mizumoto R, Ratnayake S, Strekozov B. Metastatic gastric adenocarcinoma and synchronous carcinoid tumour mimicking appendicitis: A case report. Int J Surg case Rep. 2018;44:93-7. DOI:10.1016/j.ijscr.2018.02.023.

9. Karanikas M, Kofina K, Markou M, Doukas D, Effraemidou E, Lyratzopoulos N, et al (2018). Acute appendicitis as the first presentation of appendiceal metastasis of gastric cancer-report of a rare case. J Surg case Rep (8):rjy208. DOI:10.1093/jscr/rjy208.

10. Fu K, Horimatsu T, Sano Y, Katagiri A, Kaji Y, Fujimori T. Metastasis to the appendix from gastric cancer detected incidentally on colonoscopy (2007). Endoscopy 39Suppl 1:E17. DOI: 10.1055/s2006-944904.

11. Lin CY, Huang JS, Jwo SC, Chen HY. Recurrent gastric adenocarcinoma presenting as acute appendicitis: a case report. Int J Clin Pract Supplement. 2005;147:89-91. DOI:10.1111/j.1368504x.2005.00360.x.

12. Simpson GS, Mahapatra SR, Evans J. Incidental complete excision of appendiceal gastric cancer metastasis (2013). Journal of surgical case reports 2013(10). DOI: https://doi.org/10.1093/jscr/rjt080.

13. Erçetin C, Dural AC, Özdenkaya Y, Dural Ö, Dada HG, Yeğen G, et al. Metastatic gastric signet-ring cell carcinoma: A rare cause of acute appendicitis (2016). Ulusal cerrahi dergisi 32(2):140-4. DOI: 10.5152/UCD.2015.2863.

14. Piña-Oviedo S, Del Valle L, de Leon-Bojorge B, Ortiz-Hidalgo C. 'Signet-ring' cell gastric adenocarcinoma metastatic to a neurogenous hyperplasia of the appendix (2007). Histopathology 50(5):663-5. DOI: 10.1111/j.1365-2559.2007.02628.x.

15. Sun F, Feng M, Guan W. Mechanisms of peritoneal dissemination in gastric cancer (Review) (2017). Oncol Lett 14(6):6991-8. DOI: 10.3892/ol.2017.7149.

16. Smyth EC, Nilsson M, Grabsch HI, van Grieken NC, Lordick F. Gastric cancer (2020). Lancet 396(10251):635-48. DOI: https://doi.org/10.1016/S0140-6736(20)31288-5. 
17. Hoshi H. Management of Gastric Adenocarcinoma for General Surgeons. Surg Clin North Am. 2020;100(3):523-34. DOI:10.1016/j.suc.2020.02.004.

18. Kapiev A, Rabin I, Lavy R, Chikman B, Shapira Z, Kais H, et al. The role of diagnostic laparoscopy in the management of patients with gastric cancer (2010). The Israel Medical Association journal 12(12):726-8.

\section{Tables}


Table 1

A summary of all case reports of metastatic gastric cancer to the appendix

\begin{tabular}{|c|c|c|c|c|c|}
\hline Author & Year & Presentation & Diagnosis* & Management & Outcome \\
\hline $\begin{array}{l}\text { Current } \\
\text { Case }\end{array}$ & 2021 & $\begin{array}{l}\text { Diagnostic } \\
\text { laparoscopy before } \\
\text { major gastric } \\
\text { resection }\end{array}$ & Simultaneous & $\begin{array}{l}\text { Appendicectomy, } \\
\text { chemotherapy }\end{array}$ & Alive \\
\hline $\begin{array}{l}\text { Wang et } \\
\text { al. (3) }\end{array}$ & 2021 & Acute appendicitis & Simultaneous & $\begin{array}{l}\text { Appendicectomy, } \\
\text { chemotherapy }\end{array}$ & $\begin{array}{l}\text { Died within } 6 \\
\text { months of } \\
\text { receiving } \\
\text { chemotherapy }\end{array}$ \\
\hline $\begin{array}{l}\text { Alhadid et } \\
\text { al (5) }\end{array}$ & 2020 & $\begin{array}{l}\text { Incidental during } \\
\text { another operation }\end{array}$ & Simultaneous & $\begin{array}{l}\text { Extended right } \\
\text { hemicolectomy }\end{array}$ & $\begin{array}{l}\text { Adjuvant } \\
\text { chemotherapy, } \\
\text { disease-free } \\
\text { survival } 18 \\
\text { months } \\
\text { postoperatively }\end{array}$ \\
\hline $\begin{array}{l}\text { Siddiqui } \\
\text { et al. (4) }\end{array}$ & 2020 & Acute appendicitis & 2 months & $\begin{array}{l}\text { Appendicectomy, } \\
\text { ongoing } \\
\text { adjuvant } \\
\text { chemotherapy }\end{array}$ & $\begin{array}{l}\text { No follow up } \\
\text { documented }\end{array}$ \\
\hline $\begin{array}{l}\text { Tran et al. } \\
(6)\end{array}$ & 2018 & Acute appendicitis & Simultaneous & $\begin{array}{l}\text { Appendicectomy, } \\
\text { referred for } \\
\text { chemotherapy }\end{array}$ & $\begin{array}{l}\text { No follow up } \\
\text { documented }\end{array}$ \\
\hline $\begin{array}{l}\text { Karanikas } \\
\text { et al. (7) }\end{array}$ & 2018 & Acute appendicitis & 3 years & Appendicectomy & $\begin{array}{l}\text { Disease-free } \\
\text { survival } 4 \\
\text { months post } \\
\text { appendicectomy }\end{array}$ \\
\hline $\begin{array}{l}\text { Ercetin et } \\
\text { al. (11) }\end{array}$ & 2016 & Acute appendicitis & Simultaneous & $\begin{array}{l}\text { Appendicectomy, } \\
\text { chemotherapy }\end{array}$ & $\begin{array}{l}\text { Died after } 2 \text { days } \\
\text { of chemotherapy } \\
\text { from tumour lysis } \\
\text { syndrome }\end{array}$ \\
\hline $\begin{array}{l}\text { Simpson } \\
\text { et al. (10) }\end{array}$ & 2013 & Acute appendicitis & 14 months & Appendicectomy & $\begin{array}{l}\text { Disease-free } \\
\text { survival } 2 \text { years } \\
\text { post } \\
\text { appendicectomy }\end{array}$ \\
\hline $\begin{array}{l}\text { Pina- } \\
\text { Oviedo et } \\
\text { al. (12) }\end{array}$ & 2007 & $\begin{array}{l}\text { Epigastric pain and } \\
\text { abdominal } \\
\text { discomfort, } \\
\text { simultaneous }\end{array}$ & Simultaneous & $\begin{array}{l}\text { Appendicectomy } \\
\text { and } \\
\text { cholecystectomy }\end{array}$ & $\begin{array}{l}\text { No follow up } \\
\text { documented }\end{array}$ \\
\hline $\begin{array}{l}\text { Fu et al. } \\
\text { (8) }\end{array}$ & 2007 & Anal pain & 12 months & $\begin{array}{l}\text { Systemic } \\
\text { chemotherapy }\end{array}$ & Died after 1 year \\
\hline $\begin{array}{l}\text { Lin et al. } \\
(9)\end{array}$ & 2005 & Acute appendicitis & 2 years & Appendicectomy & $\begin{array}{l}\text { Disease-free } \\
\text { survival 1-year } \\
\text { post } \\
\text { appendicectomy }\end{array}$ \\
\hline
\end{tabular}


Key: * Diagnosis - Time taken to diagnose appendiceal metastasis relative to gastric cancer

\section{Figures}
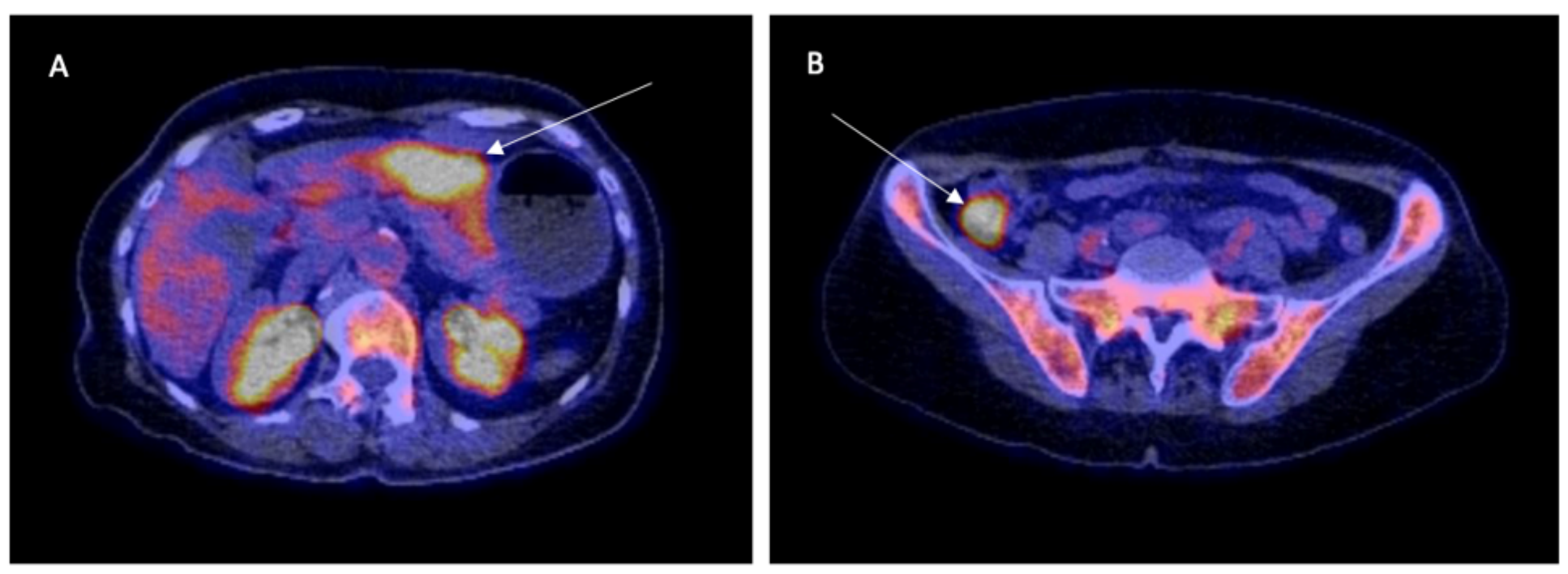

\section{Figure 1}

a: FDG PET scan. Axial cross-section with the arrow showing an intensely PET avid gastric lesion

b: FDG PET scan. Axial cross-section with the arrow denoting the caecum. Despite the PET avidity in this region, no abnormal findings on the $\mathrm{CT}$ scan led the radiologist to indicate that this was potentially physiological in nature 

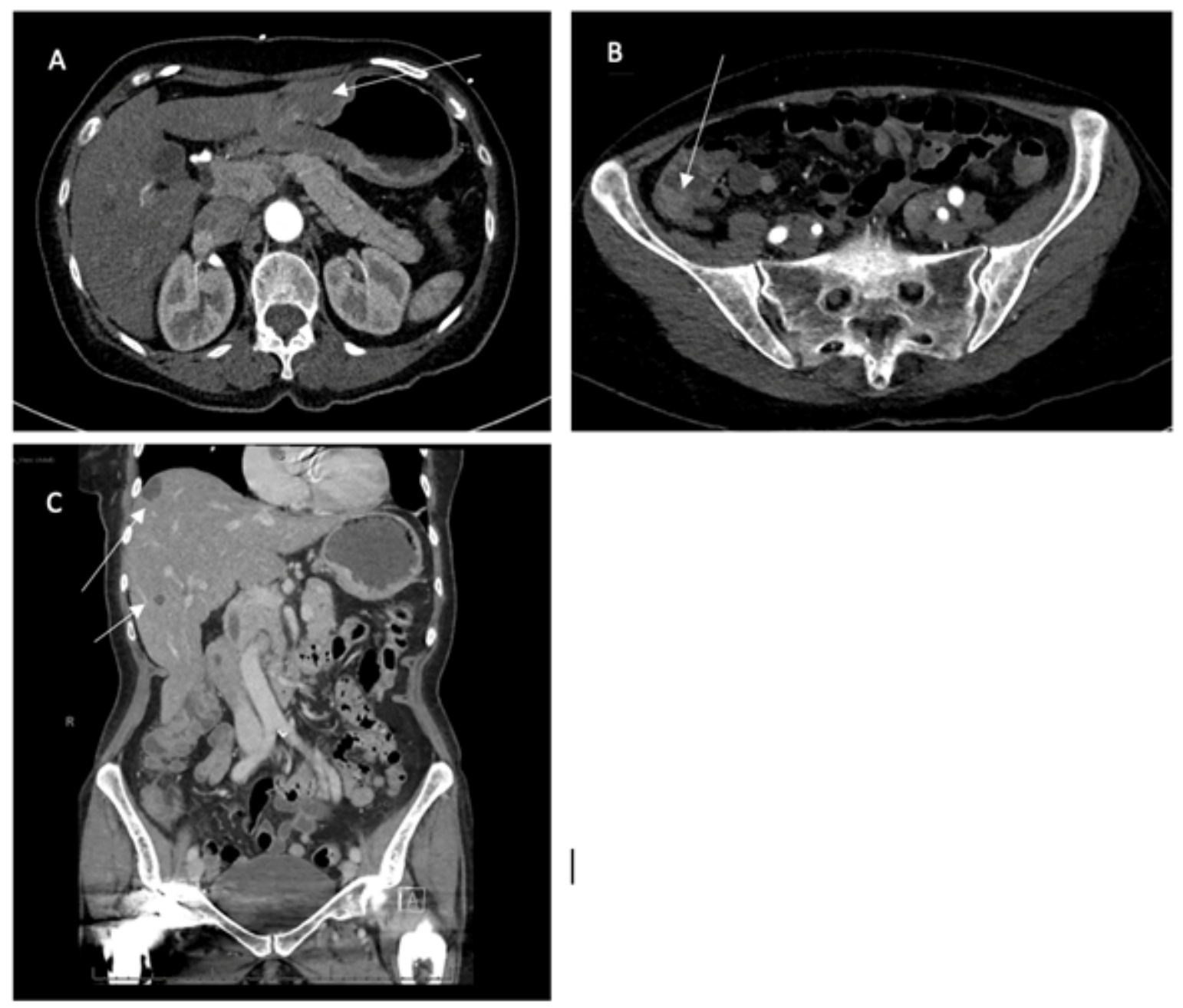

\section{Figure 2}

a: CT with IV contrast. Axial cross-section with arrow delineating circumferential thickening of the gastric antrum, consistent with the known gastric adenocarcinoma

b: CT with IV contrast. Axial cross-section with arrow denoting the caecum. No obvious abnormality, with the base of a normal-appearing appendix (diameter $-5.3 \mathrm{~mm}$ ).

c: CT with IV contrast. Coronal cross-section with arrows delineating the 2 reported subcapsular liver lesions 


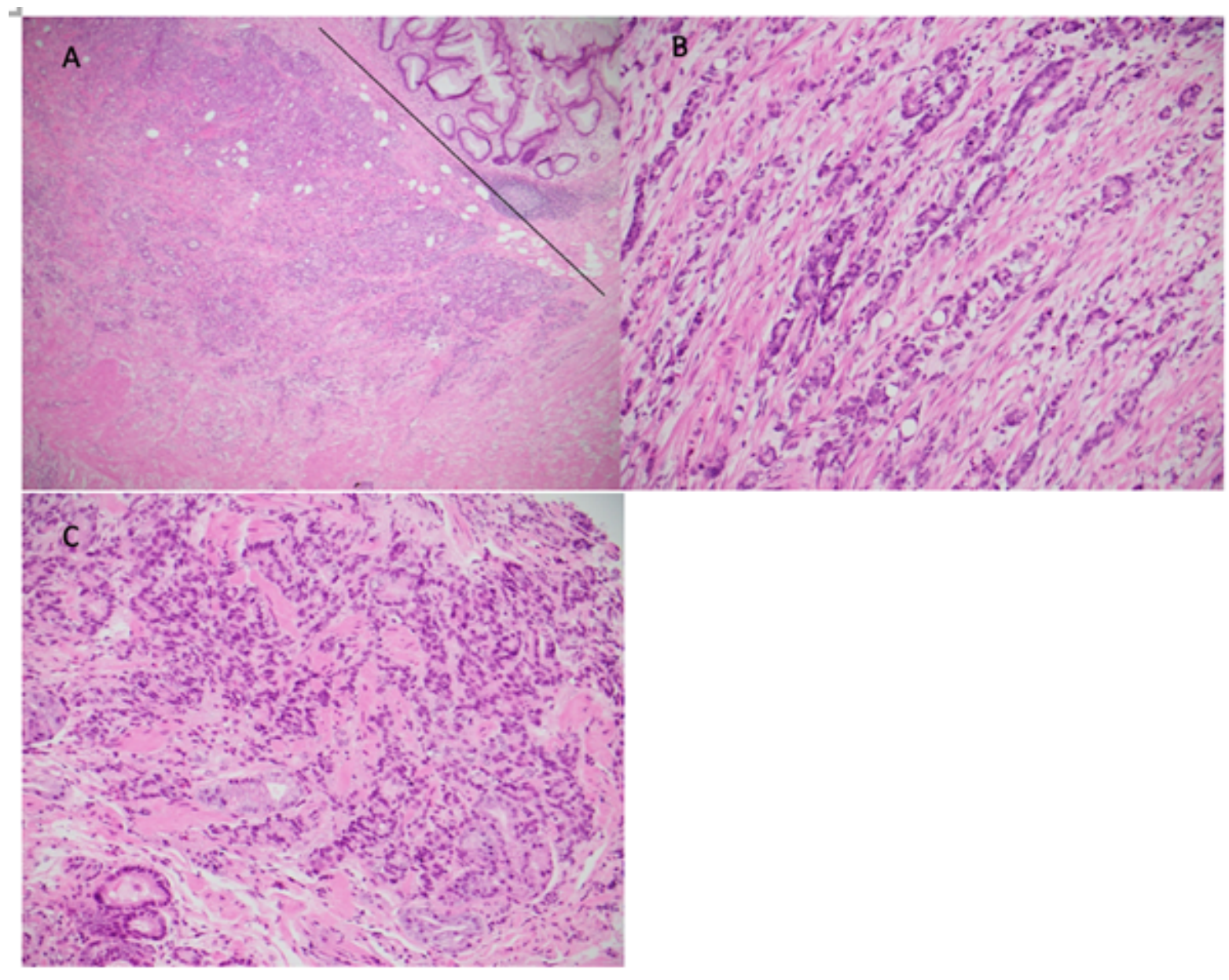

\section{Figure 3}

a: Appendix at $40 \mathrm{x}$ magnification with haematoxylin and eosin stain. Lower power image of moderate to poorly differentiated adenocarcinoma within the wall of the appendix, benign appendiceal mucosa included in the right upper corner of the image (delineated by line and *).

b: Appendix at $200 x$ magnification with haematoxylin and eosin stain. Higher power image of moderate to poorly differentiated adenocarcinoma within the wall of the appendix.

c: Gastric biopsy 200x magnification with haematoxylin and eosin stain. Higher power image of moderate to poorly differentiated adenocarcinoma within gastric biopsy; tumour predominantly in the upper $2 / 3$ of the image, intermixed with benign gastric glands. 